\title{
PROSES REFARMING FREKUENSI 1800 MHZ PHASE 1 UNTUK LAYANAN 4G LONG TERM EVOLUTION DENGAN METODE DIRECT DAN INDIRECT (STEP- WISE)
}

\section{MHZ BAND REFARMING PROCESS FOR 4G LONG TERM EVOLUTION SERVICES USING DIRECT AND INDIRECT METHOD (STEP-WISE)-PHASE 1}

\author{
R Apip Miptahudin \\ Fakultas Teknik Elektro, Universitas Muhammadiyah Tasikmalaya \\ apip@umtas.ac.id
}

\begin{abstract}
Abstrak--Pemerintah menjanjikan akan segera menyediakan aturan terkait penyediaan layanan 4G LTE (Long Term Evolution) di frekuensi $1800 \mathrm{Mhz}$. Sebelum aturan terkait tersebut dibuat, ada salah satu proses yang harus dilakukan, yaitu penataan alokasi frekuensi yang ditempati operator-operator telekomunikasi di frekuensi $1800 \mathrm{Mhz}$. Penataan ulang ini dilakukan agar operator bisa menempati blok pita frekuensi secara berurutan untuk dapat mengoptimalkan spektrum yang mereka miliki saat ini. Metode penataan ulang yang berkembang terpecah menjadi dua, yaitu direct dan indirect. Direct adalah skenario pemindahan kanal bertahap per wilayah dengan cara menggeser frekuensi serempak. Sementara indirect adalah pemindahan kanal bertahap per wilayah dengan cara menggeser frekuensi tetapi disediakan kanal kosong untuk transisi. Lebar pita di frekuensi 1800 Mhz secara keseluruhan adalah $75 \mathrm{MHz}$. XL memiliki 22,5 Mhz dalam 2 blok terpisah terpisah, Telkomsel memiliki total 22,5 MHz dengan 3 blok frekuensi yang terpisah, Indosat memiliki total $20 \mathrm{MHz}$ dengan 2 blok frekuensi yang terpisah, dan Tri memiliki total $10 \mathrm{Mhz}$ yang sudah bergabung. Proses realokasi ini perlu mekanisme perencanaan dan aturan yang jelas agar tidak menimbulkan terganggunya penyelenggaraan layanan telekomunikasi oleh operator terhadap pengguna dan menimbulkan resiko-resiko lainnya.
\end{abstract}

Kata Kunci: Refarming, Frekuensi 1800 MHz, Step-wise

\footnotetext{
Abstract--The government has promised to provide rules regarding the provision of 4G LTE (Long Term Evolution) service at $1800 \mathrm{Mhz}$ band. Before the related rules are made, there is one process that must be done, namely the arrangement of frequency allocation occupied by telecommunication operators in the $1800 \mathrm{Mhz}$ band. This rearrangement is done so that operators can occupy consecutive frequency band blocks in order to optimize their current spectrum. The method of rearrangement that developed split into two, namely direct and indirect method. Direct method is a gradual grid transfer scenario by region by shifting the frequency synchronously. While indirect method is the gradual transfer of channel by region by shifting frequency, but provided empty channel for transition. Bandwidth at $1800 \mathrm{Mhz}$ band as a whole is $75 \mathrm{MHz}$. XL has $22.5 \mathrm{Mhz}$ in 2 separate separate blocks, Telkomsel has a total of $22.5 \mathrm{MHz}$ with 3 separate frequency blocks, Indosat has a total of $20 \mathrm{MHz}$ with 2 separate Jurnal Rekayasa Sistem \& Industri Volume 4, Nomor 1, Juni 2017
}

frequency bands, and Tri has a total of $10 \mathrm{Mhz}$ already joined. This reallocation process needs clear planning and regulatory mechanisms in order to avoid disruption of telecommunication services by operators to users and pose other risks.

Keyword: Refarming, Frequency $1800 \mathrm{MHz}$, Step-wise

\section{PENDAHULUAN}

Frekuensi $900 \mathrm{MHz}$ memang jarang dimanfaatkan operator seluler di belahan dunia untuk 4G LTE, dan karena itu pula jumlah smartphone yang mendukung 900 $\mathrm{MHz}$ untuk 4G LTE masih terbatas [1]. Apalagi, lebar pita frekuensi ini terbilang kecil, totalnya hanya $25 \mathrm{MHz}$. Telkomsel dan XL masing-masing memiliki sumber daya seluas 7,5 MHz, sementara Indosat memiliki sumber daya seluas $10 \mathrm{MHz}$ [3][5][9]. Ketidakadilan dirasakan oleh Tri yang sejak dulu meminta agar pemerintah menggelar 4G LTE di frekuensi $1800 \mathrm{MHz}$ karena mereka tak punya sumber daya di $900 \mathrm{MHz}$. Secara ekosistem, $1800 \mathrm{MHz}$ adalah frekuensi yang paling populer di dunia untuk menggelar 4G LTE. Sumber daya yang dimiliki operator seluler di sana juga besar sehingga bakal ideal dalam menggelar 4G LTE. Sumber daya seluas 15 sampai $20 \mathrm{MHz}$ disebut ideal untuk menggelar 4G LTE [3][9].

Aturan terkait penyediaan layanan 4G LTE (Long Term Evolution) di frekuensi $1800 \mathrm{Mhz}$ akan segera di release oleh pemerintah. Hal ini terkait dengan rencana penggelaran 4G di $1800 \mathrm{Mhz}$ secara komersial pada pertengahan tahun ini. Namun, sebelum disediakannya aturan tersebut ada salah satu proses yang harus dilakukan, yakni penataan ulang alokasi frekuensi yang ditempati operator di $1800 \mathrm{Mhz}$. Penataan ulang ini dilakukan agar operator bisa menempati blok pita 
frekuensi secara berurutan demi mengoptimalkan spektrum yang mereka miliki.

Rencana metode migrasi/ penataan ulang alokasi frekuensi $1800 \mathrm{Mhz}$ yang berkembang terpecah menjadi dua, yaitu direct dan indirect. Direct adalah skenario pemindahan kanal bertahap per wilayah dengan cara menggeser frekuensi serempak. Sementara indirect adalah pemindahan kanal bertahap per wilayah dengan cara menggeser frekuensi tetapi disediakan kanal kosong untuk transisi [1][2].

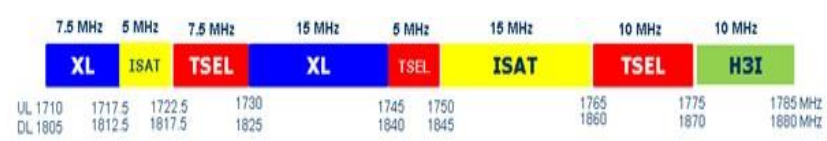

Gambar 1. Penggunaan Pita Frekuensi sebelum di realokasi

Telkomsel dan Indosat memilih indirect yang cenderung memakan waktu lebih lama. Namun XL, adalah pihak yang paling ngotot untuk direct dengan alasan "ingin cepat". Telkomsel terbilang pihak yang paling keras untuk menerapkan indirect. Penguasa seluler ini tidak mengandalkan kecepatan dalam melakukan pemindahan blok kanal, mereka mengklaim indirect menjadi langkah yang lebih aman dalam menjaga layanan $2 \mathrm{G}$ di frekuensi $1800 \mathrm{MHz}$ agar tidak terganggu. Jika layanan $2 \mathrm{G}$ terganggu karena migrasi ini, ancamannya layanan tersebut mati selama seharian atau bahkan lebih lama karena butuh pemulihan. Lebar pita di frekuensi $1800 \mathrm{Mhz}$ secara keseluruhan adalah $75 \mathrm{MHz}$. Untuk masing-masing operator yang izin penggunaan frekuensinya memiliki lebar pita yang berbeda dengan lokasi blok yang sebagian besar terpisah. XL memiliki 22,5 Mhz dalam 2 blok terpisah terpisah, Telkomsel memiliki total 22,5 $\mathrm{MHz}$ dengan 3 blok frekuensi yang terpisah, Indosat memiliki total $20 \mathrm{MHz}$ dengan 2 blok frekuensi yang terpisah, dan Tri memiliki total $10 \mathrm{Mhz}$ yang sudah bergabung.

Proses realokasi ini perlu mekanisme perencanaan dan aturan yang jelas agar tidak menimbulkan terganggunya penyelenggaraan layanan telekomunikasi oleh operator terhadap pengguna dan menimbulkan resiko-resiko lainnya. Proses realokasi ini memerlukan kehati-hatian, ketenangan, pengertian dan dukungan dari operator-operator yang terlibat dalam mekanisme realokasi penggunaan pita $1800 \mathrm{Mhz}$.

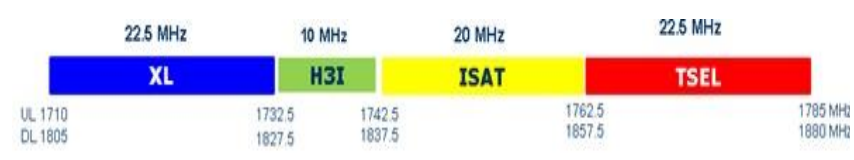

Gambar 2. Rencana Realokasi Penggunaan Pita Frekuensi 1800 MHz

Setelah realokasi diharapkan susunan blok untuk 4 operator adalah berurutan terstruktur dan tidak berpisahpisah seperti terlihat pada Gambar 2.
Kondisi saat ini adalah masih belum optimalnya penggunaan frekuensi $1800 \mathrm{MHz}$ dimana 4 operator yang akan menggunakannya untuk penggelaran LTE masih berbeda blok terpisah dalam interval bandwidth yang sempit-sempit. Di sisi lain, pemerintah meminta segera dilakukan penggelaran layanan telekomunikasi berbasis teknologi 4G/ LTE dengan alokasi frekuensi sudah ditentukan pada $1800 \mathrm{MHz}$. Hal ini memerlukan kesepakatan bersama untuk menata ulang alokasi penggunaan frekuensi $1800 \mathrm{MHz}$ oleh ke-4 operator yaitu Telkomsel, XL Axiata, Indosat dan H3I. Pemerintah harus turun tangan dalam memimpin dan menentukan mekanisme realokasi penggunaan pita frekuensi $1800 \mathrm{MHz}$ ini.

\section{STUDI LITERATUR \\ A. Long Term Evolution (LTE)}

Dalam telekomunikasi, Long-Term Evolution (LTE) merupakan standar untuk komunikasi nirkabel kecepatan tinggi untuk ponsel dan terminal data, berdasarkan GSM / EDGE dan teknologi UMTS / HSPA [1]. Hal ini meningkatkan kapasitas dan kecepatan menggunakan antarmuka radio yang berbeda bersama-sama dengan perbaikan jaringan inti. Standar ini dikembangkan oleh 3GPP (3rd Generation Partnership Project) dan ditetapkan dalam seri Rilis 8 dokumen, dengan tambahan kecil yang dijelaskan dalam rilis 9. LTE adalah jalur upgrade untuk operator dengan kedua jaringan GSM / UMTS dan jaringan CDMA2000. Frekuensi LTE berbeda dan band digunakan di berbagai negara berarti bahwa hanya multi-band ponsel dapat menggunakan LTE di semua negara di mana ia didukung.

LTE merupakan merek dagang terdaftar yang dimiliki oleh ETSI (European Telecommunications Standards Institute) untuk teknologi komunikasi data nirkabel dan pengembangan standar GSM / UMTS. Namun, negara-negara lain dan perusahaan yang berperan aktif dalam proyek LTE. Tujuan dari LTE adalah untuk meningkatkan kapasitas dan kecepatan jaringan data nirkabel menggunakan DSP baru (digital signal processing) teknik dan modulasi yang dikembangkan sekitar pergantian milenium. Tujuan selanjutnya adalah desain ulang dan penyederhanaan arsitektur jaringan untuk sistem berbasis IP dengan signifikan mengurangi perpindahan latency dibandingkan dengan arsitektur 3G. Antarmuka nirkabel LTE tidak kompatibel dengan jaringan $2 \mathrm{G}$ dan $3 \mathrm{G}$, sehingga harus dioperasikan pada spektrum radio yang terpisah.

\section{B. Pita Frekuensi FDD dan TDD LTE}

Spektrum FDD membutuhkan sepasang band, salah satu uplink dan satu untuk downlink, dan TDD memerlukan sebuah band tunggal sebagai uplink dan downlink berada di frekuensi yang sama tapi dipisahkan. Akibatnya, ada alokasi pita LTE yang berbeda untuk 
TDD dan FDD. Dalam beberapa kasus band-band ini mungkin tumpang tindih, dan oleh karena itu layak, meskipun tidak mungkin bahwa baik TDD dan FDD transmisi bisa hadir pada pita frekuensi LTE tertentu [2]. Kemungkinan besar adalah bahwa ponsel UE atau tunggal akan perlu untuk mendeteksi apakah TDD atau transmisi FDD harus dilakukan pada band tertentu. UE yang berkeliaran mungkin mengalami kedua jenis pada band yang sama. Oleh karena itu mereka akan perlu untuk mendeteksi jenis transmisi yang dilakukan pada band LTE tertentu di lokasi saat ini.Alokasi frekuensi LTE berbeda atau LTE pita frekuensi yang dialokasikan nomor. Saat ini band LTE antara 1 \& 22 yang spektrum berpasangan, band yaitu FDD, dan LTE antara $33 \& 41$ yang spektrum berpasangan, yaitu TDD.

\section{Refarming Frekuensi}

Refarming adalah istilah yang digunakan untuk proses yang mengatur dan menata kembali pita frekuensi yang secara historis telah dialokasikan untuk layanan mobile 2G (menggunakan teknologi GSM) untuk generasi baru dari teknologi mobile, termasuk generasi ketiga (menggunakan teknologi UMTS) dan generasi keempat (menggunakan teknologi LTE) [3]. Frekuensi yang telah ditata ulang dapat digunakan untuk pembaharuan teknologi sehingga dapat memudahkan operator seluler mengadopsi teknologi baru dengan memanfaatkan frekuensi yang tersedia. Teknik yang digunakan adalah dengan menggeser dan menghilangkan frekuensi yang sedang dipakai untuk dapat digunakan kembali.

\section{METODOLOGI}

Terkait realokasi frekuensi $1800 \mathrm{MHz}$, para operator yang terlibat masih memperdebatkan metode migrasi dan terpecah menjadi dua, yaitu direct dan indirect. Direct adalah skenario pemindahan kanal bertahap per wilayah dengan cara menggeser frekuensi serempak. Sementara indirect adalah pemindahan kanal bertahap per wilayah dengan cara menggeser frekuensi tetapi disediakan kanal kosong untuk transisi [1][2].

Telkomsel dan Indosat memilih indirect yang cenderung memakan waktu lebih lama. Namun XL, adalah pihak yang paling ngotot untuk direct dengan alasan "mau cepat". Telkomsel terbilang pihak yang paling keras untuk menerapkan indirect. Penguasa seluler ini tidak mengandalkan kecepatan dalam melakukan pemindahan blok kanal, mereka mengklaim indirect menjadi langkah yang lebih aman dalam menjaga layanan $2 \mathrm{G}$ di frekuensi $1800 \mathrm{MHz}$ agar tidak terganggu. Jika layanan $2 \mathrm{G}$ terganggu karena migrasi ini, ancamannya layanan tersebut mati selama seharian atau bahkan lebih lama karena butuh pemulihan. Telkomsel dan Indosat memilih indirect karena jika terjadi masalah dalam proses pemindahan sumber daya kanal ini, masih ada ruang untuk kembali ke kanal yang lama dan segera mengatasi masalah pada layanan $2 \mathrm{G}$.

Sementara itu, yang paling gencar memilih opsi direct adalah XL Axiata. Alasannya, XL ingin segera memakai sumber dayanya seluas $15 \mathrm{MHz}$ di 1800 $\mathrm{MHz}$ untuk 4G LTE. Sumber daya $15 \mathrm{MHz}$ itu didapatkan setelah XL menyelesaikan akuisisi terhadap Axis senilai $\$ 865$ juta bulan Maret 2014 lalu. Sumber daya seluas $15 \mathrm{MHz}$ itu bisa disebut masih "nganggur" alias belum dimaksimalkan.

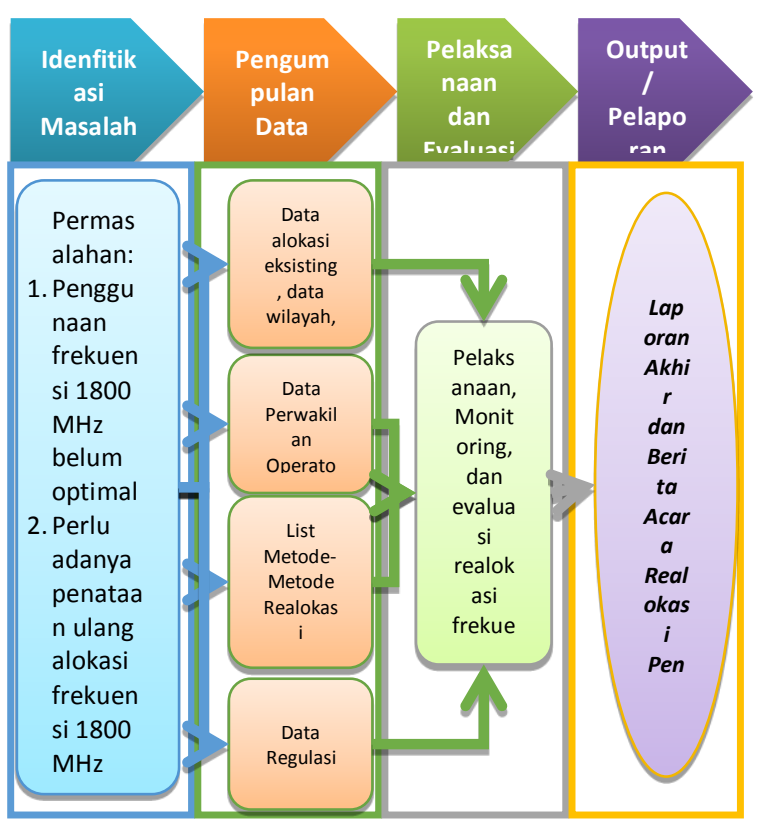

Gambar 3. Susunan kerangka realokasi

Pada metode direct, realokasi dilakukan dengan memindahkan blok kanal secara langsung dan bersamaan, sedangkan pada metode indirect, realokasi menggunakan spektrum persinggahan sehingga diklaim lebih aman bagi sebagian operator. Metode alternatif sebagai solusi jika metode direct dan indirect tidak bisa menyatukan semua operator adalah metode step-wise. Metode step-wise merupakan penggabungan dari direct dan indirect. Metode alternatif ini rencananya diterapkan ketika operator melakukan realokasi di 42 cluster yang telah ditentukan. Sebelumnya, untuk melakukan penataan ulang kanal frekuensi, metode step-wise ini pernah dijalankan di Australia beberapa waktu lalu.

Mekanisme pelaksanaan realokasi penggunaan pita frekuensi radio $1800 \mathrm{MHz}$ melalui 5 tahapan utama yaitu tahap persiapan, pelaksanaan, pengawasan (monitoring), evaluasi, dan pelaporan. Susunan kerangka (framework) dalam mekanisme realokasi penggunaan pita frekuensi $1800 \mathrm{MHz}$, dapat di lihat pada Gambar 3 dibawah ini. 


\section{HASIL PENELITIAN}

A. Data Pendukung Penataan Frekuensi

Pada penataan frekuensi fase 1 dilaksanakan sinkronisasi dan penataan frekuensi per cluster dan berkoordinasi dengan 3 operator yaitu Indosat, XL Axiata, dan Tri (3). Penataan frekuensi fase 1 ini dilakukan pada 15 wilayah/cluster. Daftar cluster yang dilakukan penataan frekuensi, dapat dilihat pada Tabel 1.

TABEL 1

NAMA CLUSTER PENATAAN FREKUENSI

\begin{tabular}{|c|l|}
\hline NO & \multicolumn{1}{c|}{ CLUSTER } \\
\hline 1 & Naggroe Aceh \\
\hline 2 & Kalimantan Selatan \\
\hline 3 & Kalimantan Tengah \\
\hline 4 & Kalimantan Timur \\
\hline 5 & Kalimantan Utara \\
\hline 6 & Kep Riau \\
\hline 7 & Maluku \\
\hline 8 & Maluku Utara \\
\hline 9 & NTB \\
\hline 10 & NTT \\
\hline 11 & Papua \\
\hline 12 & Papua Barat \\
\hline 13 & Sulawesi Barat \\
\hline 14 & Sulawesi Selatan \\
\hline 15 & Sulawesi Tenggara \\
\hline
\end{tabular}

B. Identifikasi Perangkat Operator Per Cluster

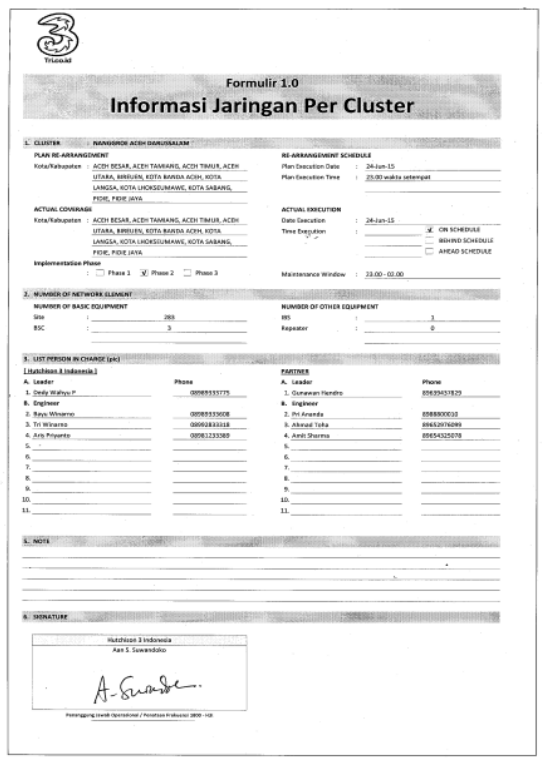

Gambar 4. Contoh Form 1.0 Informasi Jaringan per Cluster

Pada tahap ini diidentifikasi informasi jaringan per cluster terkait jumlah perangkat dasar (basic equipment) dan jumlah perangkat tambahan. Basic equipment diantaranya data jumlah site dan jumlah BTS, sedangkan perangkat tambahan LBS dan repeater. Pada tahap ini ada form yang di isi oleh masing-masing perwakilan dan operator lengkap dengan tanggal rencana eksekusi lengkap dengan waktu/ jam nya. Contoh form isian pada tahap ini (form 1.0) dapat dilihat pada Gambar 4.Penyajian data informasi jadingan per cluster pada jaringan Hutchison 3 Indonesia (Tri) dapat dilihat pada Tabel 2.

TABEL 2

INFORMASIJARINGANTRI(3) PER CLUSTER

\begin{tabular}{|l|c|c|c|c|}
\hline \multicolumn{1}{|c|}{ CLUSTER } & SITE & BSC & IBS & REPEATER \\
\hline Naggroe Aceh & 283 & 3 & 1 & 0 \\
\hline Kalimantan Selatan & 375 & 3 & 5 & 1 \\
\hline Kalimantan Tengah & 90 & 2 & 3 & 0 \\
\hline Kalimantan Timur & 368 & 3 & 18 & 4 \\
\hline Kalimantan Utara & N/A & N/A & N/A & N/A \\
\hline Kep Riau & 307 & 1 & 22 & 3 \\
\hline Maluku & N/A & N/A & N/A & N/A \\
\hline Maluku Utara & N/A & N/A & N/A & N/A \\
\hline NTB & 322 & 2 & 6 & 2 \\
\hline NTT & N/A & N/A & N/A & N/A \\
\hline Papua & N/A & N/A & N/A & N/A \\
\hline Papua Barat & N/A & N/A & N/A & N/A \\
\hline Sulawesi Barat & 37 & 1 & 0 & 0 \\
\hline Sulawesi Selatan & 747 & 4 & 22 & 5 \\
\hline Sulawesi Tenggara & N/A & N/A & N/A & N/A \\
\hline
\end{tabular}

Penyajian data informasi jadingan per cluster pada jaringan Indosat dapat dilihat pada Tabel 3.

TABEL 3.

INFORMASIJARINGAN INDOSAT PER CLUSTER

\begin{tabular}{|l|c|c|c|c|}
\hline \multicolumn{1}{|c|}{ CLUSTER } & SITE & BSC & IBS & REPEATER \\
\hline Aceh & 24 & 6 & 0 & 0 \\
\hline Kalimantan Selatan & 100 & 4 & 4 & 0 \\
\hline Kalimantan Tengah & 118 & 7 & 0 & 0 \\
\hline Kalimantan Timur & 186 & 7 & 13 & 0 \\
\hline Kalimantan Utara & 6 & 2 & 0 & 0 \\
\hline Kepulauan Riau & 140 & 6 & 6 & 0 \\
\hline Maluku & 38 & 2 & 0 & 0 \\
\hline Maluku Utara & 37 & 2 & 0 & 0 \\
\hline NTB & 42 & 1 & 0 & 0 \\
\hline NTT & 22 & 1 & 0 & 0 \\
\hline Papua & 59 & 1 & 0 & 0 \\
\hline Papua Barat & 32 & 2 & 0 & 0 \\
\hline Sulawesi Barat & 34 & 3 & 0 & 0 \\
\hline Sulawesi Selatan & 820 & 15 & 0 & 0 \\
\hline Sulawesi Tenggara & 95 & 6 & 0 & 0 \\
\hline
\end{tabular}

Penyajian data informasi jadingan per cluster pada jaringan XL Axiata dapat dilihat pada Tabel 4. 
TABEL4.

INFORMASIJARINGAN XL AXIATA PER CLUSTER

\begin{tabular}{|l|c|c|c|c|}
\hline CLUSTER & SITE & BSC & IBS & REPEATER \\
\hline Aceh & 123 & 7 & 3 & 0 \\
\hline Kalimantan Selatan & 209 & 6 & 1 & 0 \\
\hline Kalimantan Tengah & 45 & 5 & 0 & 0 \\
\hline Kalimantan timur & 66 & 4 & 16 & 0 \\
\hline Kalimantan Utara & 5 & 1 & 1 & 0 \\
\hline Kep. Riau & 89 & 4 & 27 & 0 \\
\hline Maluku & 5 & 1 & 0 & 0 \\
\hline Maluku Utara & 0 & 0 & 0 & 0 \\
\hline NTB & 682 & 18 & 15 & 0 \\
\hline NTT & 5 & 1 & 1 & 0 \\
\hline Papua & 6 & 2 & 0 & 0 \\
\hline Papua barat & 3 & 1 & 0 & 0 \\
\hline Sulawesi Barat & 14 & 1 & 0 & 0 \\
\hline Sulawesi Selatan & 210 & 6 & 0 & 0 \\
\hline Sulawesi Tenggara & 51 & 2 & 0 & 1 \\
\hline
\end{tabular}

C. Persiapan dan Perencanaan Eksekusi Penataan Frekuensi Antar Operator

Pada tahap ini dilakukan pengecekan kesiapan setiap operator yang terlibat dalam penataan frekuensi. Waktu pelaksanaan direncanakan hari dan jamnya untuk kemudian dieksekusi sesuai rencana setelah ada pernyataan kesiapan dari semua operator yang terlibat dalam penataan frekuensi ini.

TABEL 5 .

HASIL EKSEKUSI PENATAAN FREKUENSI OPERATOR TRI(3)PER CLUSTER

\begin{tabular}{|l|l|c|}
\hline \multicolumn{1}{|c|}{ CLUSTER } & $\begin{array}{c}\text { KEBERHASILAN } \\
\text { PENATAAN } \\
\text { PER CLUSTER }\end{array}$ & SIGN. \\
\hline Aceh & Sukses tanpa fallback & AS \\
\hline Kalimantan Selatan & Sukses tanpa fallback & AS \\
\hline Kalimantan Tengah & Sukses tanpa fallback & AS \\
\hline Kalimantan timur & Sukses tanpa fallback & AS \\
\hline Kalimantan Utara & Sukses tanpa fallback & AS \\
\hline Kep. Riau & Sukses tanpa fallback & AS \\
\hline Maluku & Sukses tanpa fallback & AS \\
\hline Maluku Utara & Sukses tanpa fallback & AS \\
\hline NTB & Sukses tanpa fallback & AS \\
\hline NTT & Sukses tanpa follback & AS \\
\hline Papua & Sukses tanpa fallback & AS \\
\hline Papua barat & Sukses tanpa fallback & AS \\
\hline Sulawesi Barat & Sukses tanpa fallback & AS \\
\hline Sulawesi Selatan & Sukses tanpa fallback & AS \\
\hline Sulawesi Tenggara & Sukses tanpa fallback & AS \\
\hline
\end{tabular}

Jurnal Rekayasa Sistem \& Industri

Volume 4, Nomor 1, Juni 2017
TABEL6.

HASIL EKSEKUSI PENATAAN FREKUENSI OPERATOR INDOSATPER CLUSTER

\begin{tabular}{|l|c|c|}
\hline \multicolumn{1}{|c|}{ CLUSTER } & $\begin{array}{c}\text { KEBERHASILAN } \\
\text { PENATAAN } \\
\text { PER CLUSTER }\end{array}$ & SIGN. \\
\hline Aceh & Sukses Tanpa Fallback & JR \\
\hline Kalimantan Selatan & Sukses Tanpa Fallback & JR \\
\hline Kalimantan Tengah & Sukses Tanpa Fallback & JR \\
\hline Kalimantan timur & Sukses Tanpa Fallback & JR \\
\hline Kalimantan Utara & Sukses Tanpa Fallback & JR \\
\hline Kep. Riau & Sukses Tanpa Fallback & JR \\
\hline Maluku & Sukses Tanpa Fallback & JR \\
\hline Maluku Utara & Sukses Tanpa Fallback & JR \\
\hline NTB & Sukses Tanpa Fallback & JR \\
\hline NTT & Sukses Tanpa Fallback & JR \\
\hline Papua & Sukses Tanpa Fallback & JR \\
\hline Papua barat & Sukses Tanpa Fallback & JR \\
\hline Sulawesi Barat & Sukses Tanpa Fallback & JR \\
\hline Sulawesi Selatan & Sukses Tanpa Fallback & JR \\
\hline Sulawesi Tenggara & Sukses Tanpa Fallback & JR \\
\hline
\end{tabular}

TABEL 7.

HASIL EKSEKUSI PENATAAN FREKUENSIOPERATOR XL PER CLUSTER

\begin{tabular}{|l|c|c|}
\hline \multicolumn{1}{|c|}{ CLUSTER } & $\begin{array}{c}\text { KEBERHASILAN } \\
\text { PENATAAN } \\
\text { PER CLUSTER }\end{array}$ & SIGN. \\
\hline Aceh & Sukses Tanpa Fallback & RM \\
\hline Kalimantan Selatan & Sukses Tanpa Fallback & RM \\
\hline Kalimantan Tengah & Sukses Tanpa Fallback & RM \\
\hline Kalimantan timur & Sukses Tanpa Fallback & RM \\
\hline Kalimantan Utara & Sukses Tanpa Fallback & RM \\
\hline Kep. Riau & Sukses Tanpa Fallback & RM \\
\hline Maluku & Sukses Tanpa Fallback & RM \\
\hline Maluku Utara & Sukses Tanpa Fallback & RM \\
\hline NTB & Sukses Tanpa Fallback & RM \\
\hline NTT & Sukses Tanpa Fallback & RM \\
\hline Papua & Sukses Tanpa Fallback & RM \\
\hline Papua barat & Sukses Tanpa Fallback & RM \\
\hline Sulawesi Barat & Sukses Tanpa Fallback & RM \\
\hline Sulawesi Selatan & Sukses Tanpa Fallback & RM \\
\hline Sulawesi Tenggara & Sukses Tanpa Fallback & RM \\
\hline
\end{tabular}

Pengecekan kesiapan operator per cluster menjadi acuan bagi pihak terkait dalam hal ini 3 operator dan pemerintah (kemenkominfo) apakan eksekusi dapat dilakukan dan kapan eksekusi tersebut tepat harus dilakukan. Status yang ada pada formulir pemerikasaan kesiapan eksekusi penataan (form 1.1) adalah siap atau tidak siap, Go atau Not Go.

Dari hasil perolehan data, ke-15 cluster yang akan di tata menyatakan kesiapannya untuk dieksekusi penataan frekuensi dengan status yang diberikan adalah Go. Hasil rekap selengkapnya dari kesediaan operator 
untuk dieksekusi penataan frekuensinya dapat dilihat pada Tabel 5, Tabel 6, dan Tabel 7.

\section{Eksekusi Penataan Frekuensi Per Cluster \\ Pada tahap ini dilakukan eksekusi penataan} frekuensi oleh para perwakilan operator dengan dikoordinasi oleh tim kominfo. Hasil proses eksekusi penataan frekuensi dilaporkan oleh operator kepada tim kominfo apakan sukses atau gagal.

Hasil eksekusi penataan frekuensi oleh tiga operator akan dilaporkan dengan mengisi formulir, hasil eksekusi penataan frekuensi oleh operator Tri (3) dapat dilihat pada Tabel 5. Hasil eksekusi penataan frekuensi oleh operator Indosat dapat dilihat pada Tabel 6. Hasil eksekusi penataan frekuensi oleh operator XL Axiata dapat dilihat pada Tabel 7.

\section{KESIMPULAN}

Keputusan tata ulang frekuensi $1800 \mathrm{Mhz}$ untuk jaringan 4G LTE akhirnya sudah disepakati antar operator. Operator yang akan menata frekuensi ini ialah Telkomsel, XL, Indosat, dan Tri. Dari hasil keputusan itu, realokasi ini dimulai di wilayah Maluku dan Maluku Utara. Alasannya, karena jumlah Base Transceiver Station (BTS) dari setiap operator paling sedikit di wilayah itu. Terkait realokasi frekuensi $1800 \mathrm{MHz}$, para operator yang terlibat masih memperdebatkan metode migrasi dan terpecah menjadi dua, yaitu direct dan indirect. Pada metode direct, realokasi dilakukan dengan memindahkan blok kanal secara langsung dan bersamaan, sedangkan pada metode indirect, realokasi menggunakan spektrum persinggahan sehingga diklaim lebih aman bagi sebagian operator. Metode alternatif sebagai solusi jika metode direct dan indirect tidak bisa menyatukan semua operator adalah metode step-wise. Metode step-wise merupakan penggabungan dari direct dan indirect. Metode alternatif ini rencananya diterapkan ketika operator melakukan realokasi di 42 cluster yang telah ditentukan.

Penelitian selanjutnya dapat dilakukan refarming fvrekuensi pada alokasi band frekuensi $2100 \mathrm{MHz}$, dengan membandingkan dua metode terdahulu direct dan indirect method dengan metode atlernatif step wise.

\section{DAFTAR PUSTAKA}

[1] GSMA, $900 \mathrm{MHz}$ and $1800 \mathrm{MHz}$ Band Refarming Case Study - $\quad$ France, http://www.gsma.com/spectrum/900-mhz-and1800-mhz-band-refarming-case-study-france/, diakses pada tanggal 27 Maret 2017

[2] H.K, Deny; Mufti, Nachwan; Usman, Uke Kurniawan, Analisis Refarming Band Frekuensi Televisi Analog 700 Mhz Untuk Implementasi
Teknologi Long Term Evolution (LTE) di Indonesia, 2016.

[3] Kominfo RI, Penataan Spektrum Frekuensi Radio Layanan Akses Pita Lebar Berbasis Nirkabel (Broadband Wireless Access/BWA), White Paper, Jakarta 2006.

[4] Perdana, Doan., Muayyadi, Ali., Mufti, NAchwan., Chumaediyah, Endang., Analisa Kelayakan Refarming Frekuensi $2100 \mathrm{MHz}$ dengan Analisis Prediksi Cakupan Feasibility Analysis Refarming Frequency $2100 \mathrm{MHz}$ with Coverage Estimation Analysis, www. Media.neliti.com/media/ publication, 2014

[5] Permen Kominfo RI No 25 Tahun 2014, Alokasi Spektrum Frekuensi Radio Indonesia, 2014

[6] Radio Electronics, LTE Frequency Bands \& Spectrum Allocations, http://www.radioelectronics.com/info/cellulartelecomms/lte-longterm-evolution/Ite-frequency-spectrum.php

[7] Salim Iwan, Krisnadi Irwan, Kajian Regulasi alokasi Spektrum Frekuensi Millimeter-Wave Banduntuk Akses Komunikasi 5G, 2017

[8] Septiana, Ratna., Nugroho, T. Arif., Yulius., Strategi Refarming Frekuensi $1800 \mathrm{MHz}$ untuk LTE di Indonesia, Jurnal Telematika Vol 8 No 2 ITHB, Bandung 2016.

[9] Setia, Deny, DR., Alokasi Frekuensi, Kebijakan dan Perencanaan Spektrum Indonesia, 2010

[10] Wikipedia, LTE (telecommunication), https://en.wikipedia.org/wiki/LTE_(telecommunic ation), diakses pada tanggal 27 Maret 2017, diakses pada tanggal 27 Maret 2017. 